- Original Article

\title{
Association of 10-Year Atherosclerotic Cardiovascular Disease Risk Score with Carotid Intima-Media Thickness and Plaque
}

Dong-Goo Lee, Jee-Hye Han*, Kil-Young Kwon, Jung-Hwan Kim, Kun-Hee Han, Eun-Ji Lee

Department of the Family Medicine, Eulji General Hospital, Eulji University School of Medicine, Seoul, Korea

Background: The aim of this study was to determine the association between carotid intima-media thickness (IMT) and newly developed 10-year atherosclerotic cardiovascular disease (ASCVD) risk score.

Methods: Participants were 201 Korean adults who underwent carotid ultrasonography at the Health Promotion Center of the Eulji General Hospital. We obtained information about medical history and lifestyle, and conducted laboratory tests. Carotid IMT by B-mode ultrasonography was measured. Carotid injury was considered present when the maximum carotid IMT was $\geq 0.9 \mathrm{~mm}$ or when arteriosclerotic plaques were detected. The 10-year ASCVD risk score was calculated using the 2013 American College of Cardiology/American Heart Association guidelines.

Results: Men had higher 10-year ASCVD risk score than did women (mean \pm standard deviation: $7.15 \pm 6.04$ vs. $2.53 \pm 3.67$, respectively; $\mathrm{P}<0.001$ ). Ten-year ASCVD risk was significantly correlated with right maximum carotid IMT $(\mathrm{r}=0.307)$, left maximum carotid IMT $(\mathrm{r}=0.230)$, right mean carotid IMT $(\mathrm{r}=0.322)$, and left mean carotid IMT $(\mathrm{r}=0.264)$. The group with high 10-year ASCVD risk were at even higher risk of carotid injury than were the group with low 10-year ASCVD risk (odds ratio, 2.201; 95\% confidence interval, 1.162-4.1706; $\mathrm{P}=0.019$ ). Only 10-year ASCVD risk score was significantly associated with carotid injury (odds ratio, 4.104; 95\% confidence interval, 1.57010.729). Variables that were not included in the 10-year ASCVD risk score were not significantly associated with carotid injury.

Conclusion: The findings of this study suggest that 10-year ASCVD risk score is associated with carotid injury.

Keywords: Atherosclerosis; Cardiovascular Diseases; Carotid Intima-Media Thickness; Carotid Artery Plaque 


\section{INTRODUCTION}

Atherosclerotic changes in the carotid arteries generally reflect systemic atherosclerosis and are predictive of atherosclerotic diseases such as cerebrovascular and coronary artery disease. ${ }^{1-4)}$ Measurement of carotid intima-media thickness (IMT) by Bmode ultrasonography is an early diagnostic method of subclinical atherosclerosis and an independent predictor of myocardial infarction and stroke. ${ }^{2,4-8)}$

Carotid IMT measurement by B-mode ultrasonography is easy to obtain, requires less training before application, and produces highly reproducible results; thus, this method has considerable clinical utility. ${ }^{9-12)}$ The Framingham risk score (FRS) is a widely used tool to identify asymptomatic individuals who are at risk of cardiovascular disease. Indeed, previous studies have confirmed the relationship between the FRS and carotid IMT. $^{13-15)}$

The American College of Cardiology (ACC) and the American Heart Association (AHA) developed new guidelines for cardiovascular risk assessment in 2013. ${ }^{16)}$ Because the FRS derived in an exclusively white sample population and has limited scope of the outcome (in determining coronary heart disease [CHD] alone), it was excluded from the guidelines. Rather, the Working Group derived risk equations from communitybased cohorts that are broadly representative of the United States population of whites and African Americans, and focused on estimation of first, hard atherosclerotic cardiovascular disease (ASCVD) events (defined as first occurrence of nonfatal myocardial infarction, CHD death, or fatal or nonfatal stroke. ${ }^{16)}$ The variables in the equation of 10-year risk for ASCVD event, include age, sex, race, total cholesterol, high density lipoprotein (HDL) cholesterol, systolic blood pressure, whether the patient is undergoing treatment of hypertension or diabetes, and current smoking status.

No study has evaluated the 10-year ASCVD risk score and carotid atherosclerosis in Koreans. Therefore, we aimed to investigate the association between newly developed ASCVD risk estimation and carotid IMT.

\section{METHODS}

\section{Subjects}

From January 2013 to December 2014, 7,673 adults visited the Health Promotion Center of the Eulji General Hospital in Seoul, Korea. Among them, 206 adults underwent carotid ultrasound: 201 patients were included in the analysis and five patients who had known cardiovascular disease (myocardial infarction or stroke) were excluded.

\section{Clinical Examination and Blood Assays}

Lifestyle and medical history were recorded by self-adminis- trated questionnaires. With regard to smoking status, participants were classified as non-smokers or current smokers. We collected medical history, including hypertension, diabetes mellitus, and use of lipid lowering therapy.

Height and weight were measured using an automatic digital stadiometer. Body mass index was calculated as weight in kilograms divided by height in meters squared. Blood pressure (BP) measurements were performed with an automated sphygmomanometer, with the participants seated. Blood samples were obtained after the participants had fasted for $\geq 8$ hours. The laboratory tests included total cholesterol, triglyceride, HDL cholesterol, low density lipoprotein (LDL) cholesterol, and fasting glucose levels.

\section{Measurement of Carotid Intima-Media Thickness}

The same, trained sonographer ultrasonically evaluated the carotid artery using an $8 \mathrm{MHz}$ linear array transducer (HP Sonos-5500; Philips Medical Systems, Andover, MA, USA) after the participant had been resting in the supine position for 15 minutes. Carotid IMT was measured using semi-automatic IMT measurement software (M'ATH software, version 2.01; METRIS Co., Argenteuil, France) on a computer.

The IMT was measured $2 \mathrm{~cm}$ proximal to the carotid bifurcation along at least $1 \mathrm{~cm}$ of axial length, and then an automated edge-detection algorithm quantified the IMT as the distance between the lumen-intima interface and the media-adventitia interface. The maximal and mean values of the right and left carotid IMTs were used for the analysis. A plaque was defined as a localized protrusion into the vessel lumen with thickening of the vessel wall of $>50 \%$ compared to either the adjacent IMT or an IMT thickness of more than $1.5 \mathrm{~mm}$. Carotid injury was considered to be present when either the maximum carotid IMT was greater than $0.9 \mathrm{~mm}$ or carotid plaques were detected. ${ }^{17)}$

\section{Estimation of 10-Year Atherosclerotic Cardiovascular Disease Risk Score and 10-Year Atherosclerotic Cardiovascular Disease Risk Stratification}

The 10-year ASCVD risk score was calculated by the Pooled Cohort Equations for non-Hispanic whites, which included age, sex, total cholesterol level, HDL cholesterol, systolic BP (using different coefficients, depending on whether or not the individual was treated for hypertension), current smoking status, and the presence or absence of diabetes mellitus. These allowed us to stratify the study samples into two groups: those with low 10-year ASCVD risk group (10-year ASCVD risk score $<7.5 \%$ ) and those with high 10-year ASCVD risk group (10-year ASCVD risk score $\geq 7.5 \%$ or those with diabetes mellitus). ${ }^{16,18)}$

\section{Statistical Analysis}

All data were presented in the form of mean and standard de- 
viation for all quantitative variables, or frequency and percentage for all qualitative variables. Participants were divided by sex into two groups. T-tests and chi-square tests were performed to compare the two groups. Pearson correlation analyses were used to evaluate associations between carotid IMT and 10-year ASCVD risk score for total participants and for each gender. Chi-square tests were used to evaluate associations between the high 10-year ASCVD risk group and either the high carotid IMT group or the carotid injury group, for total participants. Logistic regression analyses were performed to determine whether the carotid injury was associated with the ASCVD risk score and with other variables that are not included within the equation of 10-year risk for ASCVD score.10-year ASCVD risk score, glucose levels, and triglycerides were logtransformed because they were not normally distributed.

All analyses were two-tailed and $\mathrm{P}<0.05$ was considered statistically significant. Statistical analyses were performed using the PASW SPSS ver. 18.0 (SPSS Inc., Chicago, IL, USA).

\section{RESULTS}

The number of total participants was 201, 144 were men and 57 were women. BMI, waist circumference, triglycerides, and fasting glucose levels were significantly higher among men than they were among women. HDL cholesterol levels were significantly higher in women than they were in men. Men had higher 10-year ASCVD risk score than did women (7.15 \pm 6.04 vs. $2.53 \pm 3.67, \mathrm{P}<0.001$ ) (Table 1).

Table 2 shows the correlations between carotid IMT and 10- year ASCVD risk score. Among all participants, 10-year ASCVD risk was significantly correlated with right maximum carotid IMT $(r=0.307)$, left maximum carotid IMT $(r=0.230)$, right mean carotid IMT $(r=0.322)$, and left mean carotid IMT $(r=0.264)$. Among men, the right maximum carotid IMT $(r=0.310)$, left maximum carotid IMT $(\mathrm{r}=0.270)$, right mean carotid IMT $(\mathrm{r}=$ 0.325), and left mean carotid IMT ( $r=0.286)$ were significantly correlated with 10-year ASCVD risk score. In women, the carotid IMT was not correlated with 10-year ASCVD risk score.

Table 2. Correlations between 10-year atherosclerotic cardiovascular disease risk score and variables including CIMT thickness

\begin{tabular}{|c|c|c|c|}
\hline Variable & Total $(n=201)$ & Men $(n=144)$ & Women $(n=57)$ \\
\hline Age & $0.575^{\star \star}$ & $0.627^{\star \star}$ & $0.787^{\star \star}$ \\
\hline Body mass index & 0.134 & 0.047 & $0.264^{*}$ \\
\hline Waist circumference & 0.268 & 0.098 & 0.337 \\
\hline Systolic blood pressure & $0.181^{*}$ & 0.126 & $0.325^{\star}$ \\
\hline Diastolic blood pressure & 0.080 & 0.043 & 0.064 \\
\hline Total cholesterol & $0.226^{\star *}$ & 0.148 & $0.413^{\star *}$ \\
\hline Triglyceride & $0.409^{\star *}$ & $0.375^{\star \star}$ & $0.345^{\star \star}$ \\
\hline $\begin{array}{l}\text { High density lipoprotein } \\
\text { cholesterol }\end{array}$ & $-0.165^{\star}$ & -0.124 & -0.027 \\
\hline $\begin{array}{l}\text { Low density lipoprotein } \\
\text { cholesterol }\end{array}$ & 0.050 & -0.058 & $0.351^{\star *}$ \\
\hline Glucose & $0.470^{\star \star}$ & $0.441^{\star \star}$ & $0.434^{\star \star}$ \\
\hline Right maximum CIMT & $0.307^{\star \star}$ & $0.310^{\star *}$ & 0.187 \\
\hline Left maximum CIMT & $0.230^{* *}$ & $0.270^{* *}$ & 0.018 \\
\hline Right mean CIMT & $0.322^{\star \star}$ & $0.325^{\star \star}$ & 0.235 \\
\hline Left mean CIMT & $0.264^{\star \star}$ & $0.286^{\star \star}$ & 0.083 \\
\hline
\end{tabular}

Values are presented as correlation coefficient by Pearson correlation analysis. CIMT, carotid intima-media thickness.

${ }^{*} \mathrm{P}<0.05$. ${ }^{\star *} \mathrm{P}<0.01$.

Table 1. Baseline characteristics of study participants

\begin{tabular}{|c|c|c|c|c|}
\hline Characteristic & Total $(n=201)$ & Men $(n=144)$ & Women $(n=57)$ & P-value \\
\hline Age $(y)$ & $51.00 \pm 7.02$ & $50.81 \pm 6.52$ & $51.51 \pm 8.18$ & 0.523 \\
\hline Body mass index $\left(\mathrm{kg} / \mathrm{m}^{2}\right)$ & $25.16 \pm 2.92$ & $25.43 \pm 2.84$ & $24.49 \pm 3.03$ & 0.039 \\
\hline Waist circumference (cm) & $83.40 \pm 8.20$ & $85.49 \pm 7.27$ & $78.11 \pm 8.09$ & $<0.001$ \\
\hline Systolic blood pressure (mm Hg) & $122.61 \pm 14.54$ & $123.35 \pm 13.86$ & $120.74 \pm 16.12$ & 0.252 \\
\hline Diastolic blood pressure (mm Hg) & $74.15 \pm 10.10$ & $74.87 \pm 10.79$ & $72.35 \pm 11.42$ & 0.144 \\
\hline Total cholesterol (mg/dL) & $198.85 \pm 37.65$ & $201.94 \pm 38.28$ & $191.04 \pm 35.13$ & 0.064 \\
\hline Triglyceride $(\mathrm{mg} / \mathrm{dL})$ & $155.55 \pm 159.21$ & $175.24 \pm 179.43$ & $105.79 \pm 69.28$ & 0.005 \\
\hline High density lipoprotein cholesterol (mg/dL) & $50.67 \pm 12.76$ & $49.14 \pm 12.84$ & $54.54 \pm 11.80$ & 0.006 \\
\hline Low density lipoprotein cholesterol (mg/dL) & $123.26 \pm 33.70$ & $125.52 \pm 34.61$ & $117.54 \pm 30.84$ & 0.131 \\
\hline Glucose $(\mathrm{mg} / \mathrm{dL})$ & $97.23 \pm 25.15$ & $100.39 \pm 28.51$ & $89.25 \pm 9.64$ & 0.004 \\
\hline Hypertension & $39(19.4)$ & $30(20.8)$ & $9(15.8)$ & 0.439 \\
\hline Diabetes mellitus & $24(11.9)$ & $22(15.3)$ & $2(3.5)$ & 0.027 \\
\hline Lipid lowering therapy & $34(16.9)$ & $27(18.8)$ & $7(12.3)$ & 0.305 \\
\hline Current smoker & $64(31.8)$ & $62(43.1)$ & $2(3.5)$ & $<0.001$ \\
\hline Right maximum CIMT (mm) & $0.78 \pm 0.19$ & $0.79 \pm 0.20$ & $0.75 \pm 0.15$ & 0.134 \\
\hline Left maximum CIMT (mm) & $0.79 \pm 0.17$ & $0.80 \pm 0.18$ & $0.77 \pm 0.17$ & 0.301 \\
\hline Right mean CIMT (mm) & $0.72 \pm 0.15$ & $0.73 \pm 0.16$ & $0.69 \pm 0.13$ & 0.163 \\
\hline Left mean CIMT (mm) & $0.74 \pm 0.15$ & $0.74 \pm 0.16$ & $0.71 \pm 0.13$ & 0.222 \\
\hline Carotid plaque & $51(25.4)$ & $41(28.5)$ & $10(17.5)$ & 0.150 \\
\hline Carotid injury & $108(53.7)$ & $78(54.2)$ & $30(52.6)$ & 0.876 \\
\hline $10-Y e a r$ atherosclerotic cardiovascular disease risk score (\%) & $5.84 \pm 5.85$ & $7.15 \pm 6.04$ & $2.53 \pm 3.67$ & $<0.001$ \\
\hline
\end{tabular}

Values are presented as mean \pm standard deviation or number (\%). Data were analyzed by independent t-tests and chi-square tests.

CIMT, carotid intima-media thickness. 
Table 3. Comparison of ASCVD risk groups according to the carotid IMT groups and carotid injury

\begin{tabular}{|c|c|c|c|c|c|c|c|c|}
\hline & High carotid IMT & Low carotid IMT & $\mathrm{OR}(95 \% \mathrm{Cl})$ & P-value & Carotid injury & No carotid injury & $\mathrm{OR}(95 \% \mathrm{Cl})$ & P-value \\
\hline Total & $86(42.80)$ & $115(57.20)$ & & & $108(53.7)$ & $93(46.3)$ & & \\
\hline High 10-year ASCVD risk group & $29(14.40)$ & $29(14.40)$ & $1.509(0.8165-2.7879)$ & 0.188 & $39(19.40)$ & $19(9.45)$ & $2.201(1.162-4.1706)$ & 0.019 \\
\hline Low 10-year ASCVD risk group & $57(28.40)$ & $86(42.80)$ & & & $69(34.33)$ & $74(36.82)$ & & \\
\hline
\end{tabular}

Values are presented as number (\%). Data were analyzed by chi-square test.

ASCVD, atherosclerotic cardiovascular disease; IMT, intima media thickness; OR, odds ratio; $\mathrm{Cl}$, confidence interval.

Table 4. Multivariate logistic regression analyses for carotid injury

\begin{tabular}{lccc}
\hline Variable & $\begin{array}{c}\text { Odds } \\
\text { ratio }\end{array}$ & $\begin{array}{c}95 \% \text { confidence } \\
\text { interval }\end{array}$ & P-value \\
\hline $\begin{array}{l}\text { 10-Year atherosclerotic cardiovascular } \\
\text { disease risk score (In) }\end{array}$ & 4.104 & $1.570-10.729$ & 0.004 \\
$\begin{array}{l}\text { Body mass index } \\
\text { Waist circumference }\end{array}$ & 1.004 & $0.826-1.221$ & 0.965 \\
Diastolic blood pressure & 1.010 & $0.939-1.086$ & 0.797 \\
Lipid lowering therapy & 0.991 & $0.958-1.025$ & 0.598 \\
Glucose (In) & 0.922 & $0.370-2.299$ & 0.862 \\
Triglyceride (In) & 0.075 & $0.000-97.250$ & 0.479 \\
Low density lipoprotein cholesterol & 0.855 & $0.224-3.259$ & 0.819 \\
\hline
\end{tabular}

Table 3 shows that there was association between high carotid IMT and 10-year ASCVD risk score. However, the carotid injury group was significantly associated with the high 10-year ASCVD risk group (odds ratio [OR], 2.201; 95\% confidence interval [CI], 1.162-4.1706; $\mathrm{P}=0.019$ ).

Logistic regression analyses for carotid injury were performed with 10-year ASCVD risk score (ln), BMI, waist circumference, diastolic blood pressure, LDL cholesterol, lipid-lowering therapy, fasting glucose level (ln), and triglycerides (ln). Among these variables, only the 10-year ASCVD risk score (ln) was significantly associated with carotid injury (OR, 4.104; 95\% CI, 1.57010.729) (Table 4).

\section{DISCUSSION}

In recent ACC/AHA guidelines, a new ASCVD risk calculator was developed to quantitatively predict the ASCVD and to determine whether to prescribe anti-dyslipidemic agents. ${ }^{16)}$ In these guidelines, recommendations were made for the additional measurement of carotid ultrasound, high-sensitivity Creactive protein, ankle-brachial index, coronary artery calcium scoring, aortic pulse wave velocity, and circulating levels of lipoprotein. ${ }^{16)}$ This additional information may be especially useful to refine risk estimates for patients at intermediate risk of ASCVD. ${ }^{19,20)}$

Previous studies demonstrated an association between the carotid IMT and either the FRS or the 10-year coronary heart disease risk. ${ }^{13-15,19)}$ Several additional studies showed carotid IMT to be a strong predictor of cardiovascular disease. ${ }^{21-24)} \mathrm{A}$ recent study demonstrated that carotid IMT correlated with the new 10-year ASCVD risk score, in South Asians. ${ }^{18)}$
In the present study, we assessed the association between subclinical carotid atherosclerosis and 10-year ASCVD risk score in Koreans. Our results show that 10-year ASCVD risk score was significantly associated with carotid IMT in Korean people without known cardiovascular disease.

Moreover, the presence of plaque appears to be the major criterion for predicting high risk of cardiovascular disease. A meta-analysis of 11 population-based studies that included 54,336 subjects found that carotid plaque, was more strongly associated with incident CHD than was carotid IMT. ${ }^{25)}$ In the ARIC study of 13,145 participants with a mean follow-up period of 15.1 years, the addition of both plaque and common carotid artery IMT measurements to conventional risk factors improved the accuracy of risk stratification. ${ }^{7)}$

In our study, the high 10-year ASCVD risk group had no significant association with the high carotid IMT group but had significant association with the carotid injury group (carotid IMT $\geq 0.9 \mathrm{~mm}$, or presence of plaque). The association between presence of carotid injury and high 10-year ASCVD risk score validates this algorithm as a more accurate predictor of cardiovascular disease. Furthermore, these results suggest that using both carotid IMT measurement and B-mode ultrasonography detection of carotid plaque may be useful tools for refining CVD risk assessment.

This study has several limitations. As shown in Table 2, carotid IMT thickness and 10-year ASCVD risk score have no statistical correlation among women, which may be explained by the lack of consideration of other factors, such as hormonal status. ${ }^{26-28)}$ In addition, the small sample size of the group of women most likely affected the results; therefore, further study with a larger cohort, which incorporates additional factors, such as menopausal status, is required.

ASCVD risk assessment, which was based on pooled cohort data from longitudinal, community-based, epidemiological cohort studies, is applicable for African-Americans, and nonHispanic whites. ${ }^{16,29)}$ Therefore, ASCVD risk assessment with the ACC/AHA 10-year ASVCD risk score allows limited interpretation for Koreans, and suggests that future studies are needed in order to be able to apply the risk score in this population.

The cutoff value for carotid IMT in the Korean population is not yet established. Therefore, in this study, carotid injury was defined as outlined in the European Guidelines (version 2012). ${ }^{17}$ ) Additional studies are required to determine appropriate cutoff 
values of carotid IMT for Korean patients.

Despite these limitations, our study shows that the new ACC/ AHA 10-year ASVCD risk score was associated with subclinical atherosclerosis, demonstrated by carotid IMT and injury, in Koreans. Our finding suggest that clinicians may use the measurement of carotid IMT thickness and the detection of plaque by B-mode ultrasonography to monitor 10-year ASCVD risk with conventional risk factors, especially in patients at intermediate risk of ASCVD (e.g., 10-year ASCVD risk score of 5\%-7.5\%). ${ }^{16}$ )

In conclusion, carotid IMT and injury were significantly associated with the newly developed ASCVD risk score in Koreans.

\section{CONFLICT OF INTEREST}

No potential conflict of interest relevant to this article was reported.

\section{REFERENCES}

1. Salonen JT, Salonen R. Ultrasonographically assessed carotid morphology and the risk of coronary heart disease. Arterioscler Thromb 1991; 11:1245-9.

2. Simon A, Gariepy J, Chironi G, Megnien JL, Levenson J. Intima-media thickness: a new tool for diagnosis and treatment of cardiovascular risk. J Hypertens 2002;20:159-69.

3. Johnsen SH, Mathiesen EB, Joakimsen O, Stensland E, Wilsgaard T, Lochen ML, et al. Carotid atherosclerosis is a stronger predictor of myocardial infarction in women than in men: a 6-year follow-up study of 6226 persons: the Tromso Study. Stroke 2007;38:2873-80.

4. Bots ML, Hoes AW, Koudstaal PJ, Hofman A, Grobbee DE. Common carotid intima-media thickness and risk of stroke and myocardial infarction: the Rotterdam Study. Circulation 1997;96:1432-7.

5. Baldassarre D, Amato M, Bondioli A, Sirtori CR, Tremoli E. Carotid artery intima-media thickness measured by ultrasonography in normal clinical practice correlates well with atherosclerosis risk factors. Stroke 2000;31:2426-30.

6. Touboul PJ, Labreuche J, Vicaut E, Amarenco P; GENIC Investigators. Carotid intima-media thickness, plaques, and Framingham risk score as independent determinants of stroke risk. Stroke 2005;36:1741-5.

7. Nambi V, Chambless L, Folsom AR, He M, Hu Y, Mosley T, et al. Carotid intima-media thickness and presence or absence of plaque improves prediction of coronary heart disease risk: the ARIC (Atherosclerosis Risk In Communities) study. J Am Coll Cardiol 2010;55:1600-7.

8. Van der Meer IM, Bots ML, Hofman A, del Sol AI, van der Kuip DA, Witteman JC. Predictive value of noninvasive measures of atherosclerosis for incident myocardial infarction: the Rotterdam Study. Circulation 2004;109:1089-94.

9. Graham I, Atar D, Borch-Johnsen K, Boysen G, Burell G, Cifkova R, et al. European guidelines on cardiovascular disease prevention in clinical practice: executive summary: Fourth Joint Task Force of the European Society of Cardiology and Other Societies on Cardiovascular Disease Prevention in Clinical Practice (Constituted by representatives of nine societies and by invited experts). Eur Heart J 2007;28:2375-414.
10. Stein JH, Korcarz CE, Hurst RT, Lonn E, Kendall CB, Mohler ER, et al. Use of carotid ultrasound to identify subclinical vascular disease and evaluate cardiovascular disease risk: a consensus statement from the American Society of Echocardiography Carotid Intima-Media Thickness Task Force: endorsed by the Society for Vascular Medicine. J Am Soc Echocardiogr 2008;21:93-111.

11. O'Leary DH, Bots ML. Imaging of atherosclerosis: carotid intima-media thickness. Eur Heart J 2010;31:1682-9.

12. Wyman RA, Mays ME, McBride PE, Stein JH. Ultrasound-detected carotid plaque as a predictor of cardiovascular events. Vasc Med 2006;11: 123-30.

13. Amer MS, Khater MS, Omar OH, Mabrouk RA, Mostafa SA. Association between Framingham risk score and subclinical atherosclerosis among elderly with both type 2 diabetes mellitus and healthy subjects. Am J Cardiovasc Dis 2014;4:14-9.

14. Kieltyka L, Urbina EM, Tang R, Bond MG, Srinivasan SR, Berenson GS. Framingham risk score is related to carotid artery intima-media thickness in both white and black young adults: the Bogalusa Heart Study. Atherosclerosis 2003;170:125-30.

15. Kim KH, Hyun DW, Kim WS, Yang JK, Kwon TG, Bae JH. Carotid intima media thickness is associated with the Framingham risk score in Korean patients with coronary arteriosclerosis: association between IMT and Framingham risk score. Korean Circ J 2007;37:425-31.

16. Stone NJ, Robinson JG, Lichtenstein AH, Bairey Merz CN, Blum CB, Eckel RH, et al. 2013 ACC/AHA guideline on the treatment of blood cholesterol to reduce atherosclerotic cardiovascular risk in adults: a report of the American College of Cardiology/American Heart Association Task Force on Practice Guidelines. J Am Coll Cardiol 2014;63(25 Pt B):2889-934.

17. Perk J, De Backer G, Gohlke H, Graham I, Reiner Z, Verschuren M, et al. European Guidelines on cardiovascular disease prevention in clinical practice (version 2012). The Fifth Joint Task Force of the European Society of Cardiology and Other Societies on Cardiovascular Disease Prevention in Clinical Practice (constituted by representatives of nine societies and by invited experts). Eur Heart J 2012;33:1635-701.

18. Kandula NR, Kanaya AM, Liu K, Lee JY, Herrington D, Hulley SB, et al. Association of 10-year and lifetime predicted cardiovascular disease risk with subclinical atherosclerosis in South Asians: findings from the Mediators of Atherosclerosis in South Asians Living in America (MASALA) study. J Am Heart Assoc 2014;3:e001117.

19. Yoshida M, Mita T, Yamamoto R, Shimizu T, Ikeda F, Ohmura C, et al. Combination of the Framingham risk score and carotid intima-media thickness improves the prediction of cardiovascular events in patients with type 2 diabetes. Diabetes Care 2012;35:178-80.

20. Grewal J, Anand S, Islam S, Lonn E; SHARE and SHARE-AP Investigators. Prevalence and predictors of subclinical atherosclerosis among asymptomatic "low risk" individuals in a multiethnic population. Atherosclerosis 2008;197:435-42.

21. Spence JD. Ultrasound measurement of carotid plaque as a surrogate outcome for coronary artery disease. Am J Cardiol 2002;89:10B-15B.

22. Spence JD, Eliasziw M, DiCicco M, Hackam DG, Galil R, Lohmann T. Carotid plaque area: a tool for targeting and evaluating vascular preventive therapy. Stroke 2002;33:2916-22.

23. Kitamura A, Iso H, Imano H, Ohira T, Okada T, Sato S, et al. Carotid intima-media thickness and plaque characteristics as a risk factor for 
stroke in Japanese elderly men. Stroke 2004;35:2788-94.

24. Ebrahim S, Papacosta O, Whincup P, Wannamethee G, Walker M, Nicolaides AN, et al. Carotid plaque, intima media thickness, cardiovascular risk factors, and prevalent cardiovascular disease in men and women: the British Regional Heart Study. Stroke 1999;30:841-50.

25. Inaba Y, Chen JA, Bergmann SR. Carotid plaque, compared with carotid intima-media thickness, more accurately predicts coronary artery disease events: a meta-analysis. Atherosclerosis 2012;220:128-33.

26. Golden SH, Maguire A, Ding J, Crouse JR, Cauley JA, Zacur H, et al. Endogenous postmenopausal hormones and carotid atherosclerosis: a case-control study of the atherosclerosis risk in communities cohort. Am J Epidemiol 2002;155:437-45.
27. Zhou Y, Wang D, Yang X, Wang A, Gao X, Guo Y, et al. Effect of menopausal status on carotid intima-media thickness and presence of carotid plaque in Chinese women generation population. Sci Rep 2015; 5:8076.

28. Karim R, Hodis HN, Stanczyk FZ, Lobo RA, Mack WJ. Relationship between serum levels of sex hormones and progression of subclinical atherosclerosis in postmenopausal women. J Clin Endocrinol Metab 2008;93:131-8.

29. Safford MM, Brown TM, Muntner PM, Durant RW, Glasser S, Halanych $\mathrm{JH}$, et al. Association of race and sex with risk of incident acute coronary heart disease events. JAMA 2012;308:1768-74. 